\title{
Synthesis of Iron Phthalocyanine Grafted onto SBA-15 through Single Siloxane Bond and its Application in Liquid-Phase Hydroxylation of Phenol
}

\author{
Alexander Yu. Tolbin, ${ }^{\mathrm{a}, \mathrm{b} @ ~ S e r g e y ~ V . ~ S i r o t i n, ~}{ }^{\mathrm{a}}$ Irina F. Moskovskaya ${ }^{a}$ \\ Larisa G. Tomilova, ${ }^{\mathrm{a}, \mathrm{b}}$ and Boris V. Romanovsky ${ }^{\mathrm{a}}$ \\ ${ }^{a}$ M.V. Lomonosov Moscow State University, Moscow, 119991, Russia \\ ' Institute of physiologically active compounds, Russian Academy of Sciences, Moscow Region, Chernogolovka, 142432 , \\ Russia \\ ${ }^{\circledR}$ Corresponding authorE-mail: tolbin@newmail.ru
}

\begin{abstract}
Iron(III) phthalocyanine monosubstituted with trimethoxysilyl derivative was attached via covalent bonding onto SBA15 support in order to obtain catalyst for activation of environmentally friendly oxidant - hydrogen peroxide. Catalyst prepared was tested in liquid-phase oxidation of phenol at $60^{\circ} \mathrm{C}$. Covalently bonded complex exhibit higher activity than its unpendant analog.
\end{abstract}

Keywords: Phthalocyanine, iron(III) complex, SBA-15, catalysis, phenol, oxidation.

\section{Introduction}

For a long time, iron phthalocyanines are well known as efficient oxidation catalysts. However, the use of ungrafted tert-butyl-substituted iron phthalocyanine ( $\left.{ }^{\mathrm{t}} \mathrm{BuPcFe}\right)$ complexes is severely limited by the necessity of their isolation from the reaction mixtures after catalytic reactions. This drawback can be avoided by applying their immobilization upon the surface of inorganic supports such as silica gel, MCM-41 or SBA-15. Immobilization of ${ }^{\mathrm{t}} \mathrm{BuPcFe}$ can be performed through simple adsorption ${ }^{[1]}$ coordinative bonding with an anchoring group $^{[2,3]}$ and covalent bonding with surface silanol groups of the support. ${ }^{[4]}$ Both free and heterogenized ${ }^{\text {tBuPcFe complex- }}$ es have been shown to be active in oxidation of cyclohexane, ${ }^{[5]}$ phenol, ${ }^{[2]}$ 2,3,6-trimethylphenol ${ }^{[4]}$ and 2-methyl-1-naphthol. ${ }^{[6]}$ The covalent attaching of Pc complex is also possible by siloxane bond if Pc has an (alkoxy) ${ }_{3}$ Si-containing substituent. In this case siloxane bond is formed between a silicon atom of Pc and oxygen atom of support surface. Iron(III) phthalocyanine complexes symmetrically substituted by (EtO) $)_{3} \mathrm{Si}$ functional groups were described previously, ${ }^{[7]}$ but monomeric derivatives seem to be more suitable for controlled immobilization that affords a stable heterogeneous catalyst with spatially separated active iron species.

\section{Experimental}

\section{Synthesis}

2-(Trimethoxysilylpropoxymethylbenzyloxy)9(10),16(17),23(24)-tri-tert-butylphthalocyanine ligand, 1 b. $\mathrm{NaH}$ was added to the solution of $\mathbf{1 a}^{[8]}$ (Scheme 1) $(100 \mathrm{mg}, 0.122 \mathrm{mmol}$ ) in DMF $(5 \mathrm{ml})$ followed by stirring for $1 \mathrm{~h}$. Then 3-(chloropropyl)trimethoxysilan $(0.24 \mathrm{ml}, 1.220 \mathrm{mmol})$ was added dropwise and the mixture was kept for $8 \mathrm{~h}$ (TLC control). After completion of the reaction, phthalocyanine compounds were precipitated by adding water followed by chromatographic isolation of target ligand $\mathbf{1 b}$ to give $95 \mathrm{mg}(79 \%) . \mathrm{m} / \mathrm{z} 985[\mathrm{MH}]^{+}, 862\left[\mathrm{M}-\mathrm{C}_{3} \mathrm{H}_{9} \mathrm{O}_{3} \mathrm{Si}\right]^{+}, 818$ $\left[\mathrm{M}-\mathrm{C}_{6} \mathrm{H}_{15} \mathrm{O}_{3} \mathrm{Si}\right]^{+}, 802\left[\mathrm{M}-\mathrm{C}_{6} \mathrm{H}_{15} \mathrm{O}{ }_{4} \mathrm{Si}\right], 699\left[\mathrm{M}-\mathrm{C}_{14} \mathrm{H}_{24} \mathrm{O}_{4} \mathrm{Si}\right]^{+}$. UV-vis

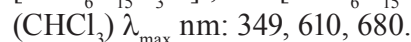

2-(Trimethoxysilylpropoxymethylbenzyloxy) 9(10),16(17),23(24)-tri-tert-butylphthalocyanine Fe ${ }^{I I I}$ acac, 2. DBU $(0.2 \mathrm{ml})$ and $\mathrm{Fe}(\mathrm{acac})_{3}(32 \mathrm{mg}, 0.092 \mathrm{mmol})$ were added to the solution of $\mathbf{1 b}(60 \mathrm{mg}, 0.061 \mathrm{mmol})$ in $o$-DCB $(10 \mathrm{ml})$, followed by heating at $150^{\circ} \mathrm{C}$ for $1.5 \mathrm{~h}$ (UV-vis and TLC control). After completion of the reaction target complex was precipitated by adding $\mathrm{CH}_{3} \mathrm{OH}$ to give $63 \mathrm{mg}(91 \%) . \mathrm{m} / z 1188$ [M-acac+DHB] $]^{+}$, 906 [M-acac- $\left.\mathrm{C}_{14} \mathrm{H}_{23} \mathrm{O}_{4} \mathrm{Si}+\mathrm{DHB}\right]$.

SBA-15. The SBA-15 material was obtained by one-step synthesis method..$^{[9]}$ Pluronic P123 $\left(\mathrm{EO}_{20} \mathrm{PO}_{70} \mathrm{EO}_{20}\right)(4 \mathrm{~g})$ was added to $110 \mathrm{ml}$ of $\mathrm{H}_{2} \mathrm{O}$ and stirred at room temperature until the dissolution was complete. Then $12.4 \mathrm{ml}$ of $0.1 \mathrm{M} \mathrm{HCl}$ and $0.01 \mathrm{~g}$ of $\mathrm{NH}_{4} \mathrm{~F}$ were added, and the mixture was heated to $40^{\circ} \mathrm{C}$. TEOS $(9.4 \mathrm{ml}, 8.8 \mathrm{~g})$ was added at vigorous stirring, then mixture was kept stirring for $72 \mathrm{~h}$ at $40^{\circ} \mathrm{C}$. Solid precipitate was washed by centrifugation until $\mathrm{pH} 4-6$. Then powder was dried at $90^{\circ} \mathrm{C}$ and calcined in mixture of $\mathrm{N}_{2}(20-30 \mathrm{ml} / \mathrm{min})$ and air $(4-5 \mathrm{ml} / \mathrm{min})$ for $24 \mathrm{~h}$ at $550^{\circ} \mathrm{C}$.

${ }^{t} \mathrm{BuPcFe}-\mathrm{Si}-\mathrm{SBA}-15$, 3. SBA-15 $(300 \mathrm{mg})$ dried at $180^{\circ} \mathrm{C}$ overnight was dispersed in $10 \mathrm{ml}$ of toluene followed by addition of $59 \mathrm{mg}$ of 2 . The mixture was refluxed for $24 \mathrm{~h}$, the powder was separated, washed with toluene and ethanol to remove the unbonded 2, then dried at $80^{\circ} \mathrm{C}$ for $24 \mathrm{~h}$. The pale green residue was obtained. Elemental analysis data (\%): N 1.1, Fe 0.55. The content of ${ }^{\mathrm{t}} \mathrm{BuPcFe}$ was calculated $-0.145 \mathrm{mmol} / \mathrm{g}$ showing $68 \%$ of phthalocyanine to be bound.

\section{Characterization}

Elemental analysis was performed using Flash EA 1112 analyzer. Sample of catalyst was placed in a tin crucible and burnt in pure oxygen followed by gas products being analyzed by GLC.

The catalytic activity was evaluated in liquid-phase oxidation of phenol by hydrogen peroxide: $1 \mathrm{~g}$ of phenol, $10 \mathrm{mg}$ of cata- 
lyst and $10 \mathrm{ml}$ of $\mathrm{H}_{2} \mathrm{O}$ were placed into static reactor equipped with thermostat. Reaction mixture was heated to $60^{\circ} \mathrm{C}$ and then $2 \mathrm{ml}$ of $25 \% \mathrm{H}_{2} \mathrm{O}_{2}$ was added. Samples of reaction mixture were collected, products were extracted with 1-butanol and analyzed using GLC with $30 \mathrm{~m}$ x $0.22 \mathrm{~mm}$ capillary SE-30 column and a FID. Activity of catalysts was expressed in $\mathrm{TOF}^{1}$ values calculated from experimental curves of phenol conversion vs. reaction time.

\section{Results and Discussion}

Initially, structure of phthalocyanine $1 \mathbf{a}^{[8]}$ was modified by nucleophilic reaction (Scheme 1, i). Further, iron(III) insertion led to complex 2 with acetylacetonate (acac) ligand as an axial substituent. The last compound was attached onto SBA-15 surface to give covalently bonded Fe ${ }^{I I I}$ phthalocyanine 3 .
The structures of compounds $\mathbf{1 b}$ and $\mathbf{2}$ were proved by mass spectrometry data. In the mass spectrum (MALDITOF) of phthalocyanine 1b molecular ion peak $(\mathrm{m} / \mathrm{z}$ 985) and all of the characteristic fragment ion peaks were detected. In addition, fragmentation is observed by consecutive breakdown of the peripheral substituent. As an example Figure 1 shows the mass spectrum of ligand $\mathbf{1 b}$. We have found for molecular ion peak of complex 2 to be replaced by secondary ion peak formed through substitution of acac by DHB matrix. Also compounds $\mathbf{1 a}$ and $\mathbf{2}$ were characterized by electron absorption spectra showing typical pattern for phthalocyanine ligand and their metallocomplex, correspondingly.

The bonding of 2 onto SBA-15 surface was evidenced by means of "CHNS"-elemental analysis. The total amount

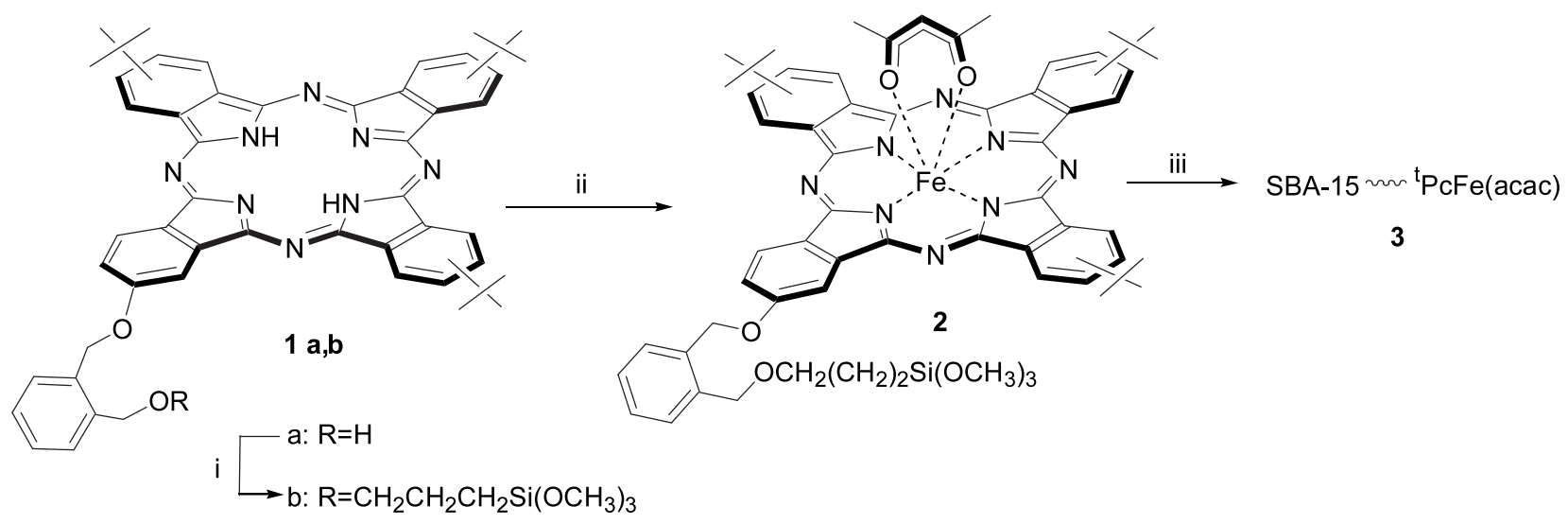

Scheme 1. Synthesis of covalently bonded $\mathrm{Fe}^{\mathrm{III}}$ phthalocyanine 3. $i$ - NaH/DMF, $\left(\mathrm{CH}_{3} \mathrm{O}\right)_{3} \mathrm{SiCH}_{2} \mathrm{CH}_{2} \mathrm{CH}_{2} \mathrm{Cl} ; i i-\mathrm{DBU} / o-\mathrm{DCB}, \mathrm{Fe}(\mathrm{acac})$; iii - SBA-15/toluene.
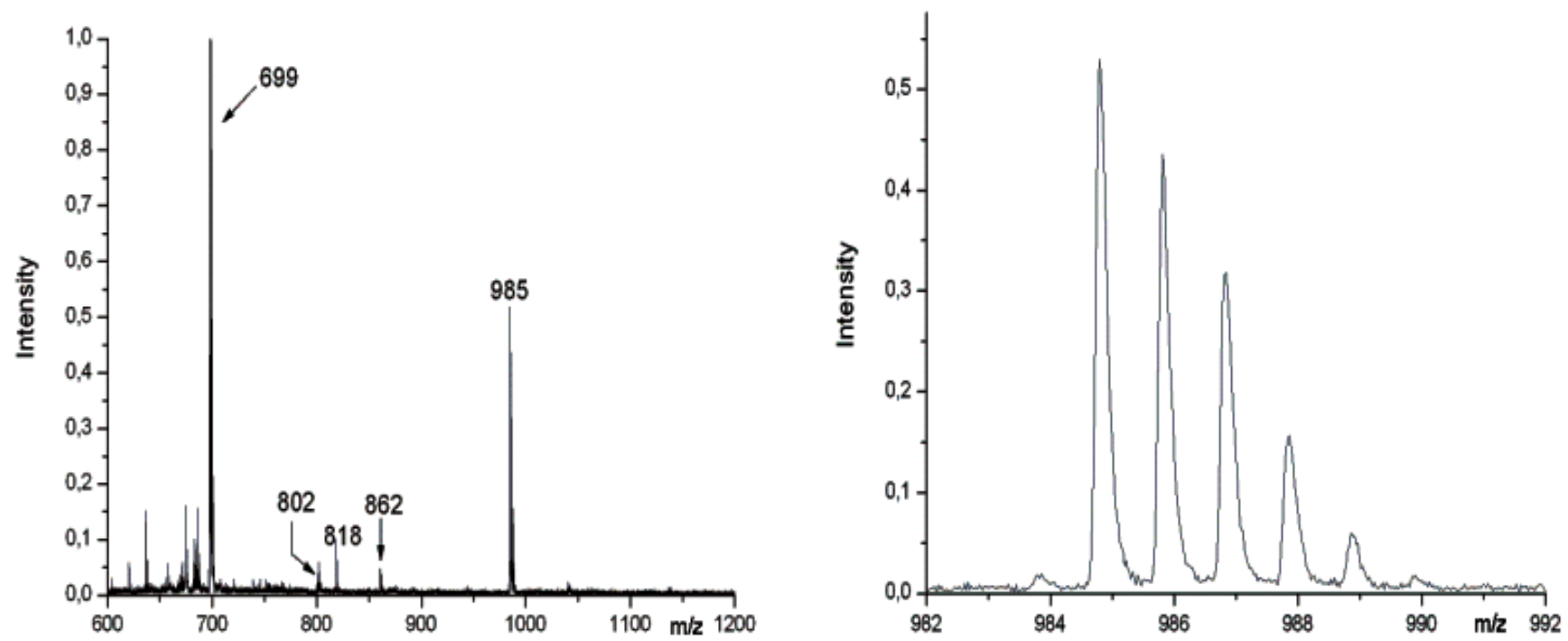

Figure 1. Mass spectrum and molecular ion peak of phthalocyanine $\mathbf{1 b}$.

Table 1. Phenol oxidation by $\mathrm{H}_{2} \mathrm{O}_{2}$ over unpendant and covalently bonded ${ }^{\mathrm{B}} \mathrm{BuPFe}-\mathrm{complexes}^{\mathrm{a}}$

\begin{tabular}{ccccc}
\hline Sample & PhOH conversion*, $\%$ & Catechol yield*, $\%$ & Hydroquinone yield*, $\%$ & $\begin{array}{c}\text { TOF**, } \\
\mathrm{mol} \mathrm{PhOH} /[\mathrm{mol} \mathrm{Fe} \times \mathrm{min}]\end{array}$ \\
\hline unpendant ${ }^{\mathrm{t}} \mathrm{BuPcFe}$ & 26 & 8 & 1 & 25 \\
$\mathbf{3}$ & 33 & 12 & 0 & 60 \\
\hline
\end{tabular}

* After $2 \mathrm{~h}$ since reaction started

** At $5 \%$ conversion of $\mathrm{PhOH}$

a SBA-15 support without 'BuPcFe-complexes don't exhibit the conversion of phenol.

${ }_{1}^{1}$ TOF - turn over frequency 
of nitrogen was used for calculation of $\mathrm{Fe}$ within ${ }^{\mathrm{t}} \mathrm{BuPcFe}$ attached amounts (see Experimental section). It is shown that $68 \%$ of ${ }^{t} \mathrm{BuPcFe}$ was condensed with surface silanol groups and thus bonded. The results of catalytic tests are summarized in Table 1. The catalysis of phenol hydroxylation by unpendant ${ }^{\mathrm{t}} \mathrm{BuPcFe}$ complex is not, in fact, homogeneous since ${ }^{\mathrm{t}} \mathrm{BuPcFe}$ is insoluble in aqueous solution. In this case, hydroxylation seems to occur on the outer surface of ${ }^{t} \mathrm{BuPcFe}$ grains. In contrast, when ${ }^{\mathrm{t}} \mathrm{BuPcFe}$ is covalently bonded to the support surface the TOF value increases by $140 \%$. In both cases, significant amounts of side products were found, supposedly, polymerized benzoquinone which could be formed directly from phenol. ${ }^{[10]}$

\section{Conclusions}

Unsymmetrically-substituted ${ }^{\mathrm{B}} \mathrm{BPcFe}$ complex containing $(\mathrm{MeO})_{3} \mathrm{Si}$ functional group was prepared and attached onto the surface of SBA-15 mesoporous molecular sieve. The catalysts with chemically bonded iron phthalocyanine as prepared by such a way were shown to exhibit higher activity in liquid phase hydroxylation of phenol than unpendant iron phthalocyanine.
Acknowledgements. This work was supported by Russian Foundation for Basic Research (projects 08-03-00544, 0803-33202) and the Federal Special Program (grant 2008-101.3-07-47). Authors also acknowledge Dr. I.V. Kolesnik for assistance in SBA-15 synthesis.

\section{References}

1. Alvaro M., Carbonell E., Esplà M., Garcia H. Appl. Catal. B 2005, 57, 37.

2. Lee C.W., Ahn D.H., Wang B., Hwang J.S., Park, S.-E. Micr. Mes. Mat. 2001, 44-45, 587.

3. De Vos D.E., Jacobs P.A. Catal. Today 2000, 57, 105.

4. Sorokin A.B., Tuel A. Catal. Today 2000, 57, 155.

5. Grootboom N., Nyokong T. J. Mol. Catal. A 2002, 179, 113.

6. Zalomaeva O.V., Kholdeeva O.A., Sorokin A.B. C. R. Chimie 2007, 10, 598.

7. Mangematin S., Sorokin A.B. J. Porphyrins Phthalocyanines 2001, 5, 674 .

8. Tolbin A.Yu., Pushkarev V.E., Nikitin G.F., Tomilova L.G. Tetrahedron Lett. 2009, in press.

9. Kim J.M., Han Y.-J., Chmelka B.F., Stucky G.D. Chem. Comm. 2000, 2437.

10. Sapunov V.N., Litvintsev I.Yu., Mikhailyuk A.I. Kin. Catal. 1998, 39, 3, 339 . 